\title{
Solid-liquid Separation of Activated Sludge by Flotation Using Microporous Ceramic Diffuser
}

\author{
S. W. Hong ${ }^{1}$, C. Park ${ }^{2}$, T. H. Chung ${ }^{3}$ \& Y. S. Choi ${ }^{4}$ \\ ${ }^{1.2 \times+}$ Center for Environmental Technology Research, Korea Institute of Science and Technology, P.O.Box 131, \\ Cheongryang, Seoul 130-650, Republic of Korea \\ ${ }^{1 \ll}$ Department of Civil, Urban \& Geo-Systems Engineering, Seoul National University, San 56-1, Sillim-dong, \\ Gwanak-gu, Seoul 151-744, Republic of Korea
}

\begin{abstract}
Dissolved air flotation (DAF) is the most widely used to separate particles from liquid. However, the main disadvantage of DAF systems is the increased operating cost due to the energy requirements for the high pressure water recycling and air compressing. In this study, alumina-based porous ceramic diffusers which can produce microbubbles at low pressure regions have been developed in order to separate and thicken activated sludge solids. No bubble was generated at lower pressure $(<0.2$ bar), whereas too large bubbles were generated at higher than 2.0 bar. At 1.8 bar, more than $70 \%$ of the bubbles had a diameter ranged from 20 to $60 \mu \mathrm{m}$. According the experimental results, the separation and thickening efficiency was mainly dependant on solid loading rate (SLR) and air to solid (A/S) ratio. When the sludge with a concentration of exceeding $5,000 \mathrm{mg} / \mathrm{L}$ was continuously fed into the flotation tank, the thickened concentration was measured to be higher than $20,000 \mathrm{mg} / \mathrm{L}$, while SS concentrations in the clarified effluent were ranged from 5 to $10 \mathrm{mg} / \mathrm{L}$. The experimental results revealed that the use of microporous ceramic diffusers could provide an economical, easy and reliable means of separating suspended solids (e.g., biological flocs) from liquid.
\end{abstract}

Keywords: Activated sludge, ceramic diffuser, flotation, microbubbles, separation

\subsection{INTRODUCTION}

The flotation process was originated from the minerals' processing field to selectively separate different minerals from another using stable froths before applied to water/wastewater engineering, mainly as a solid-liquid separation technique. Main applications in this field have been in the removal of the solids, ions, macromolecules and fibers, and other materials from water [1, 2]. In flotation, those substances are forced to collide and finally get trapped by rising air bubbles, resulting in a highly concentrated foam layer at the surface [1].

* Correspondence to: Y. S. Choi (email: yschoi@kist.re.kr)
There are two conventional flotation techniques: electroflotation (EF) and DAF. EF is a basic and effective process that floats pollutants to the surface of water using microbubbles of hydrogen and oxygen gases generated from the electrolysis of water. EF has been applied at an industrial scale for the separation of light colloidal particles, emulsified oil, ions from water $[2,3]$. In DAF, microbubbles are formed by a reduction in pressure of water pre-saturated with air at pressures higher than atmospheric (usually higher than 3 atmospheres). The supersaturated water is forced through needle valves, and clouds bubbles having $0.02-0.15 \mathrm{~mm}$ in diameter are produced. This process is widely used in the treatment of industrial wastewaters for the removal or separation of metal ions, anions, oil, 
greases, chemicals, microorganisms, colloids and ultrafines [4-6].

Flotation offers process advantages over sedimentation, including better treated-water quality, rapid startup, high rate operation, less space requirement, and thicker sludge. Therefore, it has been occasionally adapted in water and wastewater treatment process when the removal and/or separation of particles by gravitational settling are not feasible. In practice, DAF is applied intensively to thicken wastewater activated sludge $[7,8]$. DAF is considered not only an alternative to sedimentation plants, but also a clarification method to improve filtration. However, the main disadvantages of DAF are the high cost of water saturation required for bubble formation and many mechanical parts to maintain.

In order to separate and thicken activated sludge, alumina-based porous ceramic diffusers which can produce microbubbles at low pressure regions have been developed and were tested at laboratory scale. In a continuous mode, the effects of applied pressure, SLR, A/S ratio, flotation time on sludge thickening and separation efficiency were investigated.

\subsection{MATERIALS AND METHODS}

\subsection{Alumina-based Porous Ceramie-Diffusers}

In order to achieve the objectives mentioned above, the microporous ceramic diffusers were made of wet powder which is a mixture of binder solution with an alumina powder. During the calcination step, the temperature of the oxidative atmosphere furnace was kept in the range of $900^{\circ} \mathrm{C}$ to $1,300^{\circ} \mathrm{C}$. Each disc-type ceramic diffuser has dimensions of an outer diameter of $152 \mathrm{~mm}$, an inner diameter of $25.5 \mathrm{~mm}$ and a thickness of $11.2 \mathrm{~mm}$, and its' surface area is $360 \mathrm{~cm}^{2}$.

\subsection{Experimental Set-up for Continuous Air Flotation}

The capability of the ceramic diffusers to float activated sludge solids by generating microbubbles was examined using a 70-liter reactor with contíńuous feeding of the activated sludge. Four disc-type diffusers were placed vertically at the bottom of the reactor (Figure 1). And air was introduced to ceramic diffuser at different pressures by using an air regulator (AFR 200-8, Parker Co. Ltd., USA).
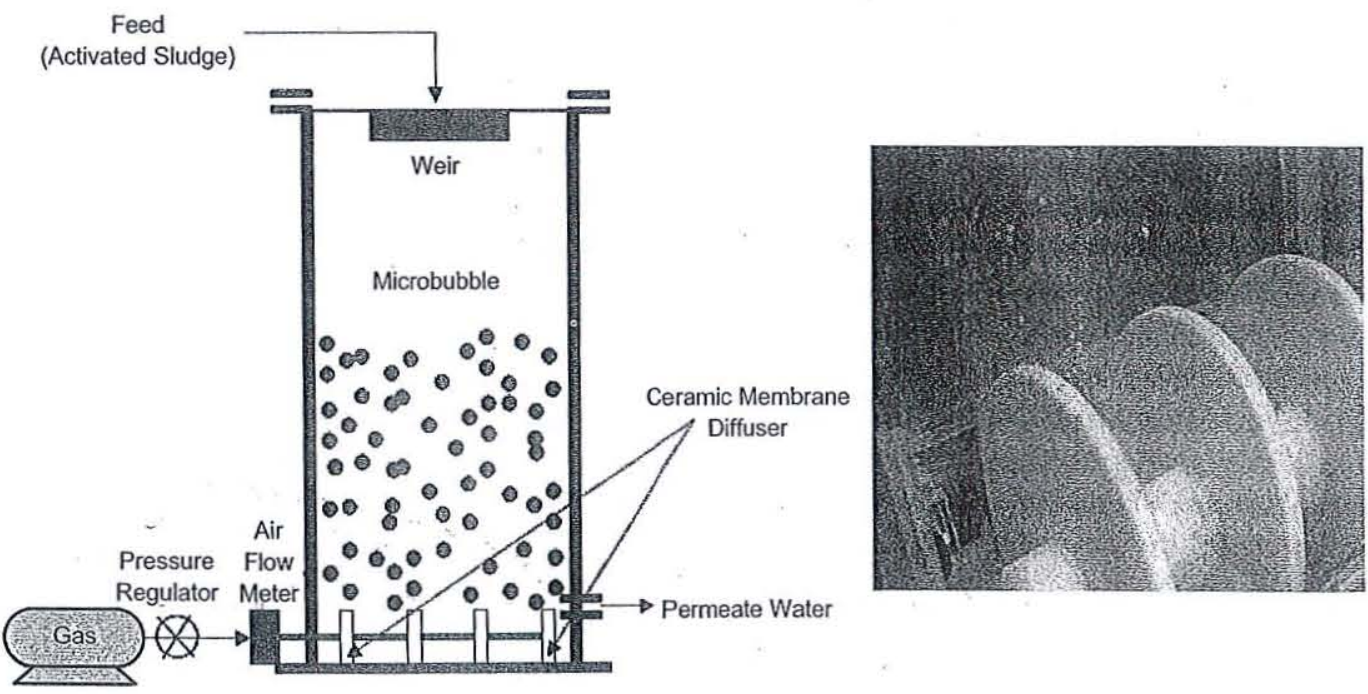

Figure 1 An apparatus for separation of sludge from suspensions by air flotation (left) and a picture of a set of diffusers (right) used in this experiment 


\subsection{Analyses}

With varying the air pressure from 0.2 to 1.8 bar, the sizes of the microbbules generated from the diffuser were measured with a particle counter (LaserTrac Model PC 2400D, Hemtrac, USA). The sludge volume index (SVI) was calculated by the following formula.

$\mathrm{SVI}=\left[\mathrm{SV}_{30}(\mathrm{ml}) / \mathrm{MLSS}(\mathrm{mg} / \mathrm{L})\right] \times 10,000$

The MLSS of mixed liquor, SS in the separated water, and solids concentration of thickened sludge bed were analyzed according to the Standard Methods for Examination of Water and Wastewater [9].

\subsection{RESULTS AND DISCUSSIONS}

\subsection{Bubble Size Distribution}

In general, bubble size has a profound effect on flotation efficiency: small air bubbles are necessary in order to increase separation efficiency. Bubbles with the size range between 5 and $220 \mu \mathrm{m}$ are very convenient for separating particles that could be found in water or wastewater $[10,11]$. Figure 2 shows the distribution of the bubble size at different inlet pressures. With an inlet pressure of 0.2 and $2.0 \mathrm{bar}$, the portion of larger bubbles $(>60 \mu \mathrm{m})$ generated from the diffuser increased. At the pressure less than 0.2 bar, no bubbles were generated while larger bubbles $(>100 \mu \mathrm{m})$ not suitable for the flotation of activated sludge were formed at higher than 2 bar. With an inlet pressure of 1.8 bar, more than $70 \%$ of the total number of bubbles sized from 20 to $60 \mu \mathrm{m}$ in diameter. Thus, the inlet pressure of 1.8 bar was selected for further experiments.

\subsection{Effect of Flotation Time}

In order to determine the effect of flotation time, floats at the top of the reactor and effluent from the reactor were collected at different times and analyzed separately. The $\mathrm{SVI}_{30}$ and the concentration of the sludge used in this experiment ranged from $120-150 \mathrm{ml} / \mathrm{g}$ and was $3,300 \mathrm{mg} / \mathrm{L}$, respectively. The concentrations of thickened MLSS and SS in the effluent were plotted in Figure 3 as a function of time. Also, the thickness of the floated sludge at the top of the reactor was plotted as a function of time (Figure 3). The thickened sludge concentration increased up to $25,000 \mathrm{mg} / \mathrm{L}$ and the thickness of the sludge also increased to about $20 \mathrm{~cm}$ with flotation time until $60 \mathrm{~min}$. However, those decreased with flotation time during the next $180 \mathrm{~min}$. This may be due to the detachment of the bottom sludge in the blanket occurred by prolonged flotation. Therefore, the effluent SS concentration increased up

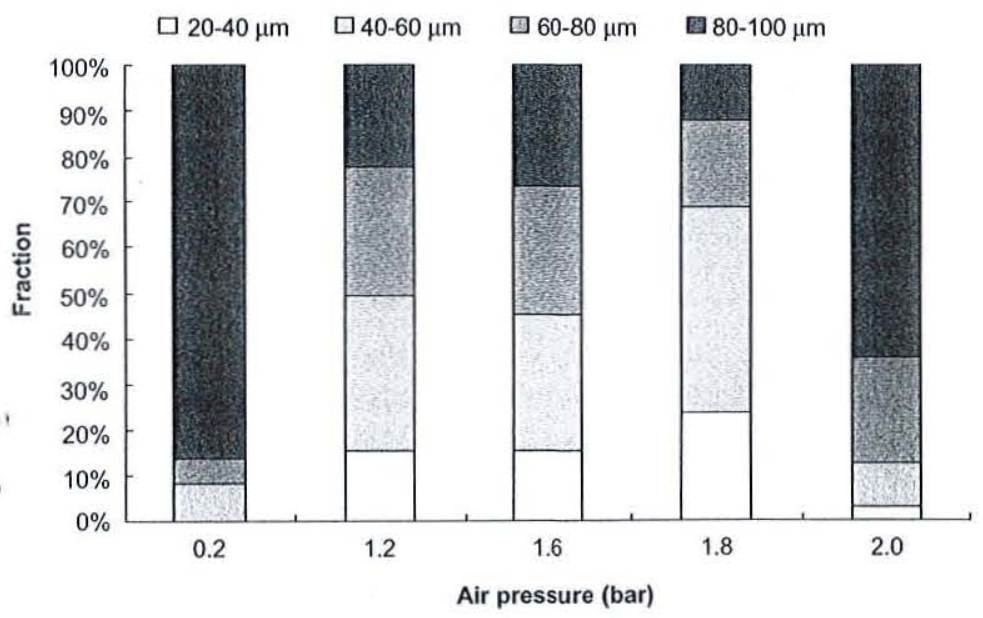

Figure 2 Size distribution of air bubbles generated by the ceramic diffuser 

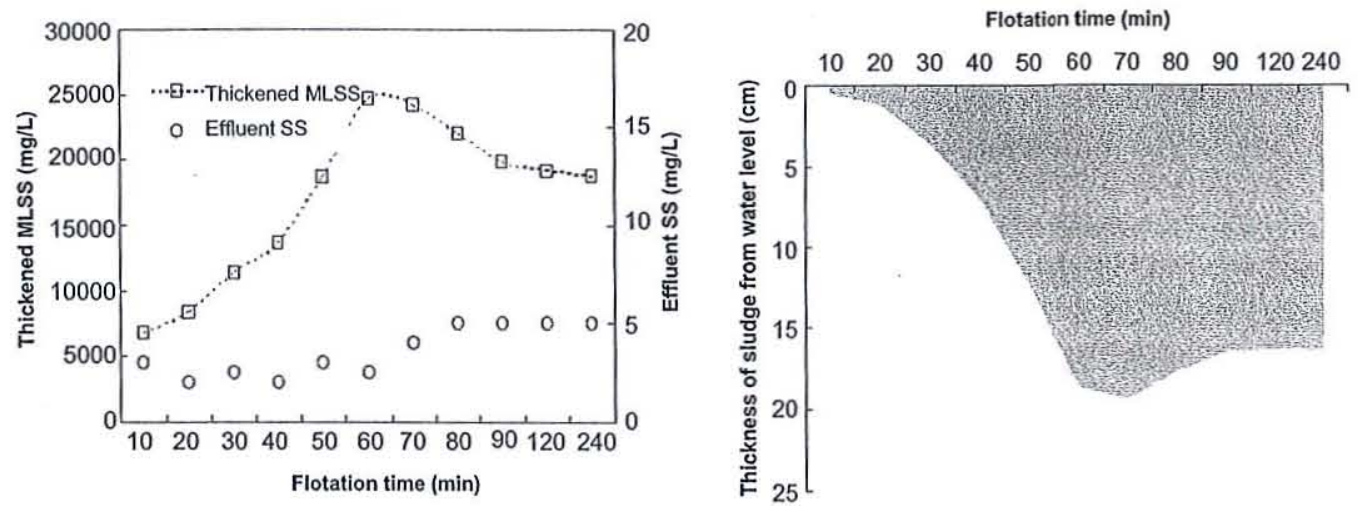

Figure 3 Variations of thickened sludge concentration (left) and thickness of sludge blanket with time (right)

to $5 \mathrm{mg} / \mathrm{L}$ when flotation time exceeded $80 \mathrm{~min}$. These results indicate that the thickened sludge at the top would be routinely skimmed off every hour in order to obtain clean effluent.

\subsection{Effect of SLR on Flotation}

Since the SLR is known to be one of important parameters in flotation processes, its effect on flotation efficiency was determined by varying the feeding rate and the influent MLSS concentration. And the concentration of thickened MLSS and the effluent SS concentration were analyzed at different loading rates. Results obtained at different loading rates are shown in Figure 4. Within the range of 0.13 to 0.21 $\mathrm{g} / \mathrm{cm}^{2} \cdot \mathrm{hr}$, the thickened MLSS concentration ranged from 15,000 to $28,000 \mathrm{mg} / \mathrm{L}$. Also, the concentration of SS in effluent kept below than $5 \mathrm{mg} / \mathrm{L}$. However, the thickened MLSS concentration decreased and the effluent SS concentration increased when the SLR exceeded 0.25 $\mathrm{g} / \mathrm{cm}^{2} \cdot \mathrm{hr}$. The optimum SLR can be enhanced by intensification of the process by, for example, increasing the number of ceramic diffusers placed at the bottom of the flotation tank.
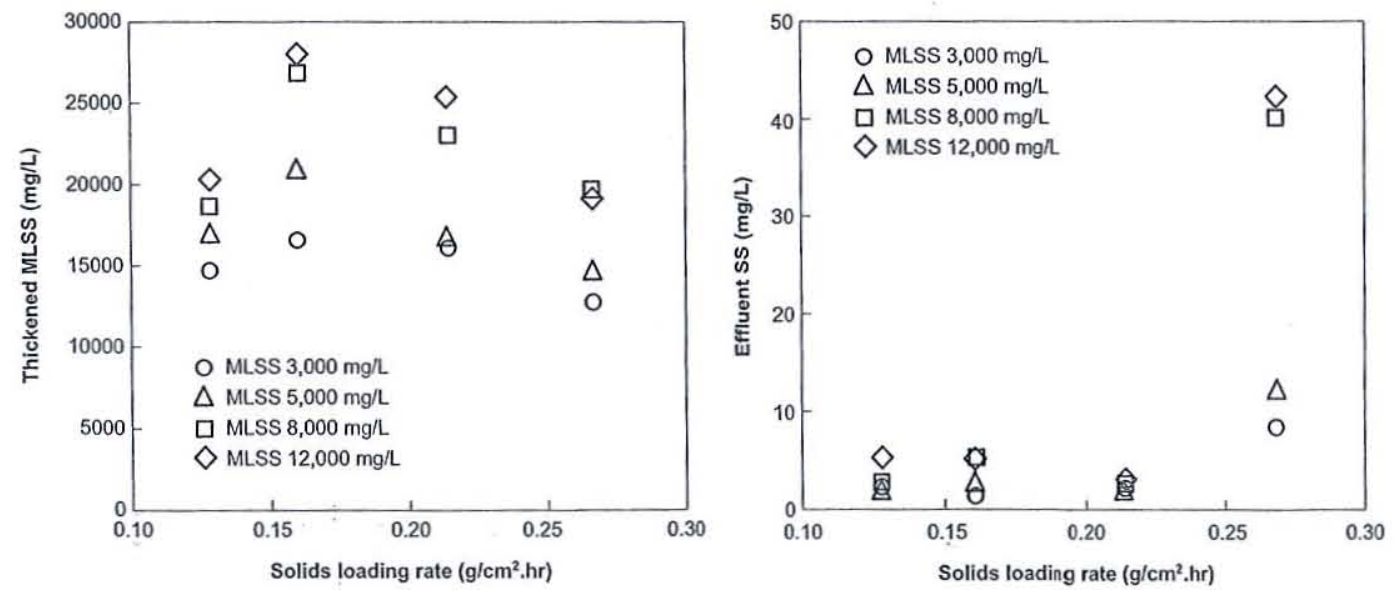

Figure 4 Solid concentration of thickened sludge (left) and effluent SS concentration (right) under various SLRs 

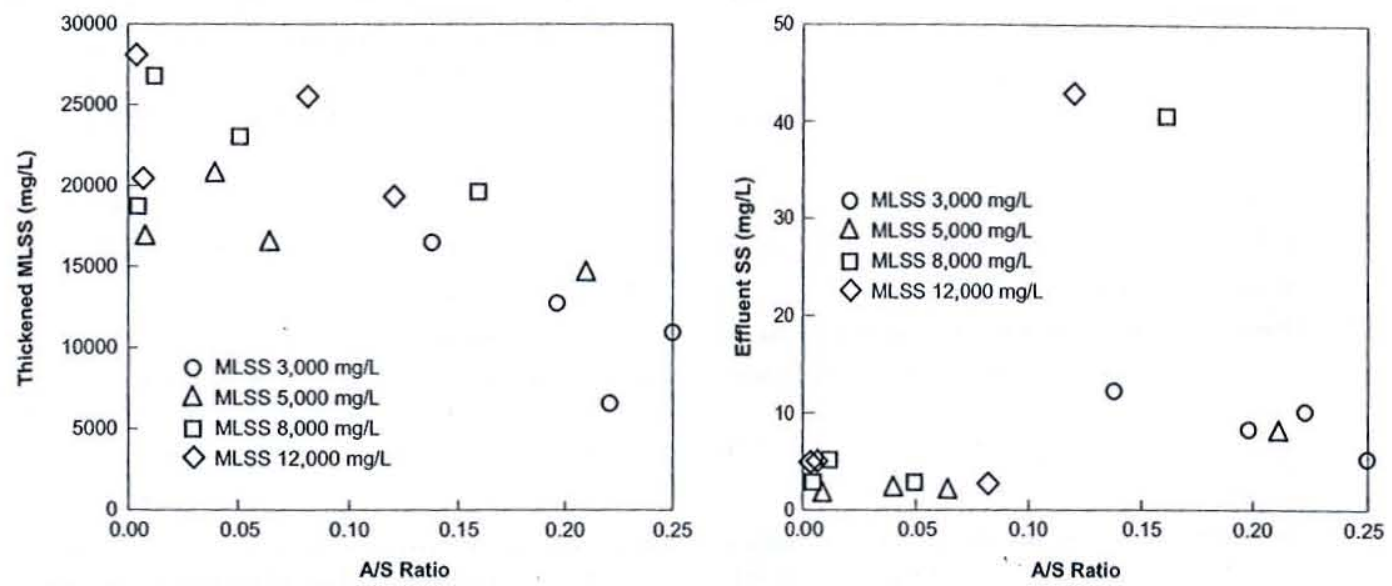

Figure 5 Solid concentration of thickened sludge (left) and effluent SS concentration (right) under various $\mathrm{A} / \mathrm{S}$ ratios

\subsection{Effect of A/S Ratio on Flotation}

The A/S ratio, defined as the amount of released air per mass of solids, has shown to be the most important factor affecting flotation efficiency [7, 12]. The effect of the A/S ratio on flotation was determined by using the ceramic diffusers. It can be seen from Figure 5 that the thickened MLSS concentration varied with the $\mathrm{A} / \mathrm{S}$ ratios. The concentration of the thickened sludge decreased when the $\mathrm{A} / \mathrm{S}$ ratio was higher than 0.2 . This may be due to turbulence created by the swarming of rising bubbles, which disrupts the sludge blanket. Thus, the SS concentrations in effluent increased. With the A/S ratio less than 0.10 , the SS concentrations in effluents were measured to be less $5 \mathrm{mg} / \mathrm{L}$. In addition, the thickened sludge concentrations were higher than $16,000 \mathrm{mg} / \mathrm{L}$.

\subsection{CONCLUSIONS}

The feasibility of separating and thickening activated sludge solids by flotation using newly developed ceramic diffusers was demonstrated. Also, effects of flotation time, SLR, and A/S ratio were determined. At an inlet pressure of $1.8 \mathrm{bar}$, the activated sludge has been successfully floated within $60 \mathrm{~min}$. In this experiment, the flotation efficiency was optimized at the solids loading rate of 0.13 to $0.21 \mathrm{~g} / \mathrm{cm}^{2} \cdot \mathrm{hr}$ and the $\mathrm{A} / \mathrm{S}$ ratio less than 0.10 . These results indicate that this flotation process can be applied as sludge thickening process as well as a primary and secondary clarifier in water/wastewater engineering field. The feasibility of this flotation technology as a secondary clarifier in combination with a biological nutrient removal process is currently under investigation.

\section{ACKNOWLEDGEMENTS}

This work was supported by the Korea Institute of Science and Technology Institutional Research Programs, and in part by Seoul National University SIR Group of the BK21 Research Program funded by the Korean Ministry of Education \& Human Resources Development. This research was also supported by a grant (code \#. $\mathrm{I}^{2}$ WATERTECH 04-5) from $\mathrm{I}^{2}$ WATERTECH of Eco-STAR Project funded by Ministry of Environment, Korea.

\section{REFERENCES}

[1] Matis, K.A. 1995. Flotation Science and Engineering. New York: Marcel Dekker. 558.

[2] Zabel, T. 1992. Flotation in Water Treatment. In Innovations in Flotation Technology. Edited by P. Mavros and K.A. Matis. 
Dordrecht, MA: Kluwer Academic Publishers. 431-454.

[3] Zouboulis, A.I., K.A. Kydros, and G.A. Stalidis. 1992. Flotation Techniques in Water Treatment. In Innovations in Flotation Technology. Edited by P. Mavros and K.A. Matis. Dordrecht, MA: Kluwer Academic Publishers.

[4] Dupre, V., M. Ponasse, Y. Aurelle, and A. Secq. 1998. Bubble Formation by Water Release in Nozzles-II: Influence on Various Parameters on Bubble Size. Water Res. 32: 2498-2506.

[5] Lazaridis, N.K., K.A. Matis, G.A. Stalidis, and P. Mavros. 1992. Dissolved Air Flotation of Metal Ions. Sep. Sci. Technol. 27: 1743-1758.

[6] Lemlich, R. 1972. Bubble Separation Techniques. New York: Academic Press.

[7] Bratby, J.R., and W.A. Ambrose. 1995. Design and Control of Flotation Thickeners. Water Sci. Technol. 31: 247-261.
[8] Gnirss, R., and A. Peter-Frölich. 1996. Biological Treatment of Municipal Wastewater With Deep Tanks and Flotation for Secondary Clarification. Water Sci. Technol. 34: 257-265.

[9] APHA. 1992. Standard Methods for Examination of Water and Wastewater. New York: American Water Work Association.

[10] Baeyens, J., Y.I. Mochtar, S. Liers, and H. De Wit. 1995. Plugflow Dissolved Air Flotation. Water Environ. Res. 67: 10281035.

[11] Dupre, V., M. Ponasse, Y. Aurelle, and A. Secq. 1998. Bubble Formation by Water Release in Nozzles-II: Mechanisms. Water Res. 32: 2491-2497.

[12] Chung, T.H., and D.Y. Kim. 1997. Significance of Pressure and Recirculation in Sludge Thickening by Dissolved Air Flotation. Water Sci. Technol. 36: 223-230. 